\title{
Integración del arte mural en la arquitectura residencial de Ricardo Carbonell
}

\author{
Ayansi Avendaño \\ Universidad Centroameric a na \\ "J osé Simeón Cañas", UCA
}

Resumen: Durante la modernidad arquitectónica en El Salvador, que tuvo su momento álgido entre 1940 y 1980, se produjo un reencuentro de la arquitectura con las artes plásticas. En este proceso, existió un caso particular de integración de la plástica en la vivienda, el del arquitecto y artista salvadoreño Ricardo Carbonell (1929), quien realizó obras murales en viviendas de carácter privado y en algunos edificios públicos. El presente trabajo se centra en el análisis de la integración plástica en la arquitectura de Ricardo Carbonell, como una forma de contribuir directamente al enriquecimiento de la identidad arquitectónica salvadoreña. Se fundamenta el abordaje de su obra desde tres aspectos clave: primero, definir la "arquitectura" como parte del "arte", para así comprender la obra mural como contribuyente en la construcción de la identidad. En segundo lugar, destacar referentes concretos de América Latina en el movimiento plástico-arquitectónico paralelos a la obra de Carbonell y, por último, se realizará un acercamiento y reflexión a la obra del arquitecto Carbonell desde sus influencias artísticas, su formación y su trabajo arquitectónico en el contexto de la modernidad.

Palabras clave: murales, arquitectura, movimiento moderno, Ricardo Carbonell, identidad, El Salvador.

Abstract: During architectural modernity in El Salvador, that had its peak between 1940 and 1980, took place a meeting between art and architecture. In this process, there was a particular case of integration of art into housing, that proposed by Ricardo Carbonell (1929), himself both an architect and artist. He made mural works in private houses and some public buildings. This article analyzes this experiment of integration by Ricardo Carbonell as a contribution to the enrichment of the identity of salvadoran architecture. His work is studied from three key aspects: first, the definition of architecture as art; second, to underline 
the conexions of concrete referents in the art-architecture movements in Latin America that were contemporary of Carbonell; and, third, a close examination of the work of Carbonell from the standpoing of his artistc influences, and his training in the context of architectural modernity.

Keywords: murals, architecture, modern movement, Ricardo Carbonell, identity, El Salvador.

\section{La arquitectura como contribución a la definición de la identidad}

El reconocimiento de los "rasgos singulares" de un grupo social es lo que define su identidad, la cual es definida por Giménez (2005) como la "apropiación distintiva de ciertos repertorios culturales que se encuentran en nuestro entorno social, en nuestro grupo o en nuestra sociedad" (p. 1). Se trata de repertorios o manifestaciones culturales que en la práctica pueden ser sumamente diversos, que van desde lo intangible hasta su materialización más concreta en lo tangible.

En la construcción del "nosotros" diferenciadora de los "otros", los aportes particulares de los individuos resultan ser los que finalmente dan forma a esa identidad, ya que, como dice Giménez (2005), la “identidad de una persona contiene elementos de lo socialmente compartido, resultante de la pertenencia a grupos y otros colectivos, y de lo individualmente único" (p. 10). De esta aclaración se desprenden dos ideas importantes: por un lado, el reconocimiento de que el "ser" es el resultado de la interacción con los grupos sociales a los cuales pertenece, de la interacción con un entorno político, económico y cultural específico en el tiempo y, por otro lado, los dones que cada persona posee para enfrentarse a ese contexto.

Hacer esta reflexión sobre la identidad y cómo ésta se encuentra relacionada de forma indisoluble con la cultura, resulta fundamental para comprender el aporte individual que el arquitecto, ingeniero y artista Ricardo Carbonell realizó a la construcción de la identidad a través de la arquitectura en El Salvador. Este aporte se puede analizar desde las integraciones plásticas de murales en su obra construida, es decir, desde los aportes tangibles de este personaje al contexto y al paisaje urbano salvadoreño.

En ese marco, resulta válido cuestionarse si la obra mural en la arquitectura de Ricardo Carbonell llega a ser sustancialmente relevante para la sociedad en la cual ha sido producida. Para 
ello es importante precisar dos grandes ideas que contribuyen a dar respuesta. Por un lado, se debe tener presente que la producción de Carbonell es el resultado tangible de un ingenio creativo único y singular, producto de su formación $y$ de experiencias personales robustecidas por la interacción con un entorno social, político y cultural único, el "período moderno" en el cual se estaban suscitando profundas transformaciones, incluso en el mundo de las artes plásticas (Gutiérrez, julio-diciembre de 2013, p. 59). Ello nos lleva a establecer la segunda idea: el reconocimiento de Ricardo Carbonell1 como uno de los exponentes de la plástica salvadoreña que se encuentra produciendo obras no únicamente a nivel de caballete, sino de una escala mucho mayor en la arquitectura.

Todo esto nos encamina a pensar que estas obras arquitectónicas pueden llegar a formar parte del amplio y diverso repertorio de bienes de interés cultural de El Salvador, ya que éstas pueden ser concebidas como parte del:

Conjunto de las obras del hombre en las cuales una comunidad reconoce sus valores específicos y particulares y con los cuales se identifica. La identificación y la especificación del patrimonio es por tanto un proceso relacionado con la elección de valores. (Carta de Cracovia, 2000, p. 5).

Según esta definición planteada desde la Carta de Cracovia sobre los Principios para la Conservación y Restauración del Patrimonio Construido, se hace especial hincapié en dos aspectos puntuales. En primer lugar que el reconocimiento del patrimonio por parte de un grupo social definido debe hacerse desde el establecimiento de los "valores culturales", lo cual solo es posible realizarlo desde el estudio histórico de estos bienes y de su contexto social, a fin de ponderar su significación; y, en segundo lugar, que será indispensable que exista una fuerte "identificación" de la sociedad con dicho patrimonio. Esto quiere decir que las comunidades deben reconocer en ese objeto ciertos "rasgos que los representan", con los cuales sienten afinidad y de los cuales incluso pueden enorgullecerse. Con esto se puede terminar de afirmar que el patrimonio, tanto tangible como intangible, contribuye a la construcción de la identidad y que, por tanto, deben considerarse productos de la misma sociedad que los engendra en determinados momentos históricos.

Aterrizando esta reflexión sobre la obra arquitectónica de Ricardo Carbonell y su posible relación con la definición de patrimonio 
cultural, debe tenerse en cuenta que dichas obras son, hasta el momento, muy poco conocidas debido principalmente a su carácter "privado" de difícil acceso y disfrute por parte de la sociedad salvadoreña. En consecuencia, no se encuentran dentro del "imaginario" de los grandes colectivos, ni tampoco éstos pueden "identificarse" con ellas, pese a que estas obras poseen valores estéticos, formales, espaciales e, incluso, históricos con los cuales la sociedad salvadoreña podría identificarse. Por dichas razones, aún no se ha reconocido su "profundo y singular valor" como aporte único a la plástica y a la arquitectura salvadoreña dentro del período de intensa producción arquitectónica de la segunda mitad del siglo XX, donde además debe considerarse que, a nivel internacional, son escasos los reconocimientos de las obras producidas durante la modernidad dentro de los catálogos de bienes culturales de diferentes países (Humanes, 2009). Es por ello que el análisis de la obra mural en la arquitectura de Ricardo Carbonell que se desarrolla a continuación busca contribuir a su reconocimiento más generalizado y al enriquecimiento de la identidad local, entorno a esta particular producción arquitectónica y artística de gran calidad de mediados de siglo XX.

\subsection{La arquitectura también es arte}

Para iniciar con las reflexiones definición propuesta por Nikolaus en torno al trabajo artístico en la Pevsner, la que el mismo Carbonell, arquitectura de Ricardo Carbonell es en un escrito sobre la "Arquitectura y necesario comenzar definiendo de su integración con las artes plásticas" formamuybrevequé es laarquitectura (Carbonell, 1964, p. 64), cita para y cómo ésta es considerada un arte. comprender las cualidades de este Para ello, podemos referirnos a una arte, donde se expresa que:

\section{[...] Casi todo lo que encierra espacio en una escala suficiente para que un hombre se mueva en él, es una construcción; el término arquitectura se aplica exclusivamente a edificios proyectados con el propósito de suscitar una emoción estética. (Pevsner, 1957, p. 11).}

Esto permite distinguir, por un lado, la diferencia entre arquitectura y construcción, la cual vendrá dada por la búsqueda o no de sensaciones en el usuario $y$, por otro lado, nos clarifica que la arquitectura será un arte útil para el desarrollo de la vida cotidiana $y$, a la vez, un medio de 
expresión estética por cuanto busca despertar a través de los sentidos del espectador diversas sensaciones y emociones, similar a lo que podría ocurrir con un cuadro o una escultura como otras formas de arte, con la gran diferencia de que, para ser experimentada, la arquitectura debe ser recorrida, efectuándose de esta manera una relación directa y estrecha entre el usuario y el espacio, mientras que un cuadro solo podrá ser percibido desde fuera.

\section{Movimientos plástico-arquitectónicos del mismo período en América Latina}

La relación entre arte y arquitectura ha sido, a través de la historia de la humanidad, una constante. Desde que el primer hombre descubrió que el muro de la cueva era el lienzo sobre el cual podía plasmar su vida, así a través de los siglos, esta estrecha relación se mantuvo íntimamente ligada hasta la llegada de la Revolución Industrial primordialmente en el continente europeo, cuyo proceso de mecanización y especialización suscitó la separación entre artistas, arquitectos, ingenieros y artesanos, produciéndose con ello una paulatina disgregación de los valores culturales que encerraba esta tradicional relación entre el arte y la arquitectura (Villanueva, octubre de 1962). Sin embargo, en América Latina, debido al atrasado proceso de actualización e intercambio con las fuentes culturales europeas, la tradicional relación entre las tres nobles artes (pintura, escultura y arquitectura) se mantuvo en una simbiosis constante alimentada por las relaciones con el viejo continente, por lo que finalmente se crea en México la Real Academia de San Carlos de la Nueva España en el año de 1781, siendo así la primera escuela de arte del continente americano que luego dará origen a otras academias de arte en Centroamérica (UNAM, 2014).

Pese a que las relaciones entre esta Academia con la de San Fernando, en España, se vio dividida a finales del siglo XVII, de ella surgieron personajes influyentes en el movimiento moderno latinoamericano de mediados de siglo XX como Diego Rivera (1886-1957), David Alfaro Siqueiros (1896-1974) y José Clemente Orozco (1883-1949), quienes comenzarán a dar forma al Movimiento Muralista mexicano en la década de 1920. Este movimiento se apoyará en las obras propuestas desde la doctrina arquitectónica "funcionalista" mexicana que cobrará mayor fuerza en la década de 1930, con la que se inicia la estrecha conjunción entre la arquitectura con este movimiento artístico (Garza, 2010). 
De este período es notorio el arquitecto y artista Juan O'Gorman (1905-1982), quien proyectó en su papel como arquitecto, algunas escuelas públicas, en las que incorporó a jóvenes artistas en el diseño de murales con absoluta libertad para expresar todas las críticas sociales que desearan (Heredia, agosto de 2014). En estos casos, O'Gorman desde la dirección, en la posición de arquitecto, permitió establecer los espacios en los cuales deberían realizarse dichos murales, localizados primordialmente en vestíbulos o descansos de escaleras. En estos sitios, se controlaba de manera precisa la distancia y el acercamiento entre el espectador y la obra, además se consideraba la velocidad con la que se transita o se aproxima hacia ella.

Esta riqueza del "ser" en la persona de O'Gorman, que abarca desde el dominio artístico al arquitectónico, le permite aprovechar la materialidad de las estructuras para plasmar obras de profundo contenido social y expresión realista para el gran público, ya que las obras se situaron mayoritariamente en edificios estatales. Este es el caso particular de impulso dado desde el contexto sociocultural mexicano de la primera mitad del siglo XX.

En esta oportunidad se robustece la concepción del potencial que posee "el muro" en la arquitectura, como medio de expresión artística de gran escala -independientemente del contenido- que, a su vez, transforma la experiencia y vivencia de los espacios, y los dota de contenidos mucho más ricos y expresivos, ya sea por su temática o por su materialidad, las cuales pueden ser sumamente diversas. En estos aspectos podemos vincular y valorar mejor la obra mural de Carbonell en sus viviendas que, si bien no logran una difusión y alcance generalizado como el de los murales mexicanos, es valiosa por el aporte que hace a la cultura y a la identidad arquitectónica salvadoreña desde su trabajo individual de escala residencial privada, lo que también debería ser ampliamente conocido y difundido.

Si bien el trabajo de O'Gorman en este primer período es destacable, el movimiento de integración plástica mexicano es mejor conocido por las obras en algunos edificios de la Ciudad Universitaria de la Universidad Nacional Autónoma de México (UNAM), en el que también formaron parte Diego Rivera y David Alfaro Siqueiros, miembros del gran equipo encargado de dar cuerpo a uno de los proyectos más relevantes de la historia de la arquitectura latinoamericana. En este proyecto son notorios los murales de la Biblioteca Central (Fig. 1), obra de los arquitectos Gustavo Saavedra, Juan Martínez de Velasco y Juan O'Gorman, este último es autor del mural Representación histórica de la cultura. Destacan también los 

el edificio de rectoría (1952-1956) y estéticas como la incorporación obra de los arquitectos Mario Pani, de piedras naturales para dar Enrique del Moral y Salvador Ortega forma a temas de fuerte contenido (Marín, 2006). En estas obras se nacionalista.

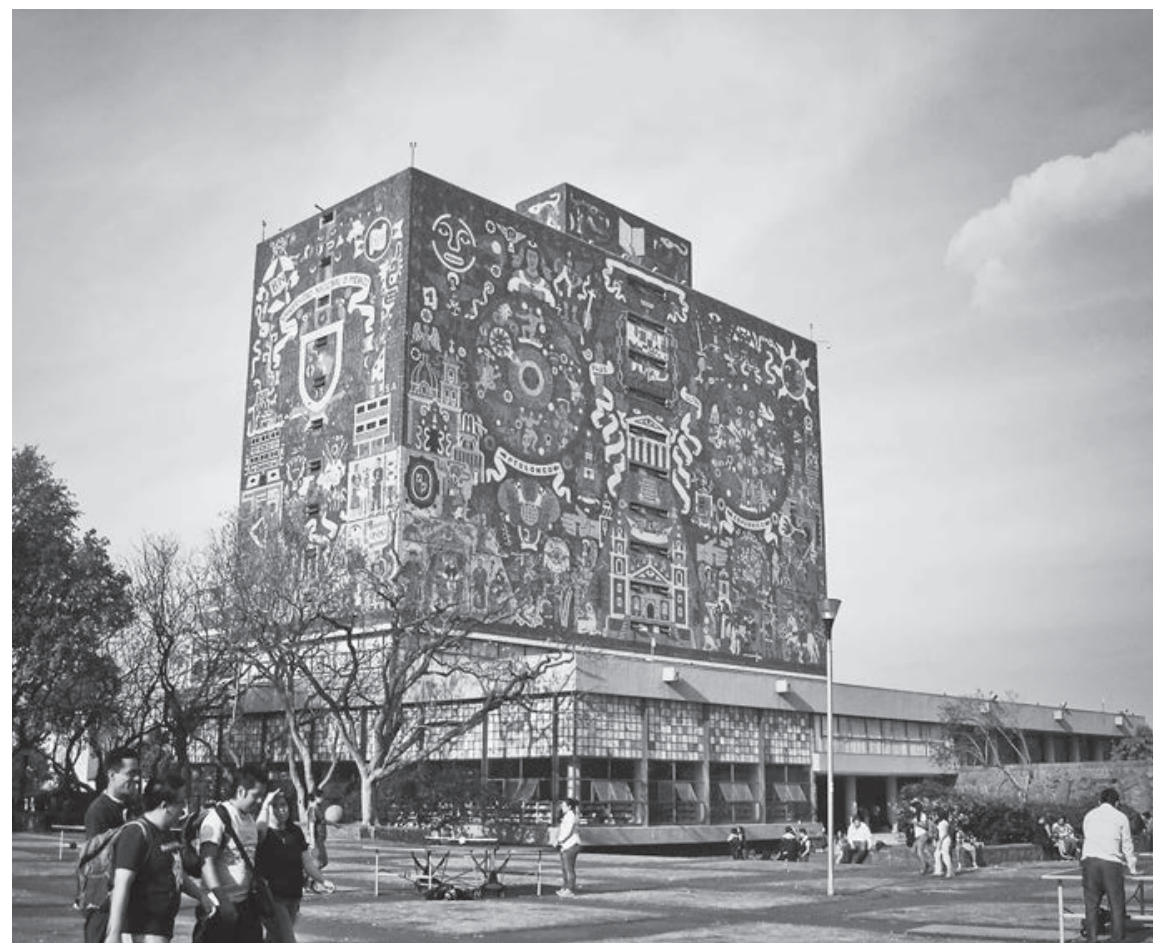

Fig. 1. Mural "representación histórica de la cultura" (1952) en la Biblioteca Central de la UNAM. Nótense las líneas modernistas del edificio en contraste con el mural de piedras naturales de O`Gorman. Fotografía de la autora, 2015.

El movimiento de integración plástica en México, según el análisis de Carlos Ríos Garza, es una muestra clara de la "búsqueda por combatir la fuerte pérdida de identidad nacional mexicana que se estaba viviendo ante la presión de la arquitectura internacional" (Garza, 2010, p. 94). Por dicha razón, se ensayó un lenguaje propio con marcada inclinación indigenista para la composición de obras murales, que contribuyeran a que la población se afirmase y se encontrase como nación. Esta situación entra en contradicción con los postulados del movimiento moderno internacional, el cual rechazaba el historicismo en 
la arquitectura por la búsqueda de una nueva estética, cuyas ideas se habían extendido rápidamente por el continente americano, incluso por El Salvador.

Enmarcados en este contexto, es importante aclarar que la experimentación mural de Ricardo Carbonell en su arquitectura no busca ratificar la identidad salvadoreña, como en el caso de México con su movimiento de integración plástica, se trata más bien de una búsqueda e inquietud personal del artista por crear obras con contenidos más abstractos y naturalistas que intensificaran la vivencia de los espacios. Ello no desmerece el aporte a la identidad arquitectónica salvadoreña que se hace desde estos murales, ya que pueden ser concebidos como exploraciones que hicieran propia y única una arquitectura de fuerte influencia del movimiento moderno internacional "anónimo", siendo así una manera de hacer "nuestra" una corriente arquitectónica universal.
De forma paralela a la corriente mexicana y a la producción de Carbonell, en El Salvador, esta relación entre las artes plásticas y la arquitectura durante el movimiento moderno es impulsada por el Estado, similar al resto de países latinoamericanos. Para ello, se crean instituciones como el Instituto de Vivienda Urbana (IVU) y la Dirección de Urbanismo y Arquitectura (DUA), las cuales se encargarán de crear obras públicas de vivienda y espacios de recreación para impulsar el "bien común". Así se promueve el trabajo conjunto entre arquitectos e ingenieros con artistas plásticos, quienes deberán incorporar en conjuntos urbanos (Fig. 2) -como miradores, parques, centros recreativos y otros- obras artísticas para el goce público (Gutiérrez, 2012, p.7).Entre estos artistas se encuentran el costarricense, nacionalizado mexicano, Francisco Zúñiga (19121998), la salvadoreña Violeta Bonilla (1924-1999) y su esposo mexicano Claudio Cevallos. Además, debe resaltarse al salvadoreño Valentín Estrada (1902-1987). 


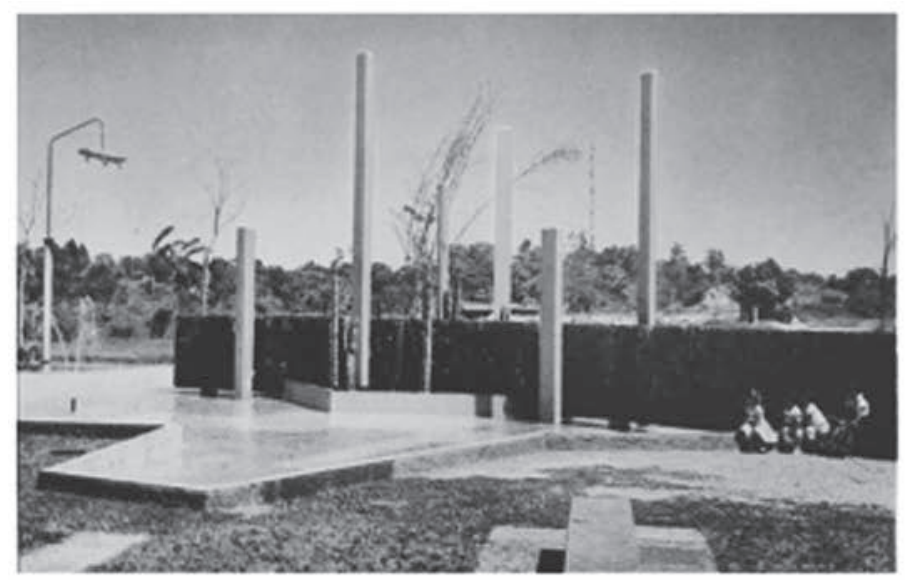

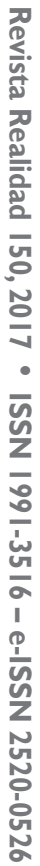

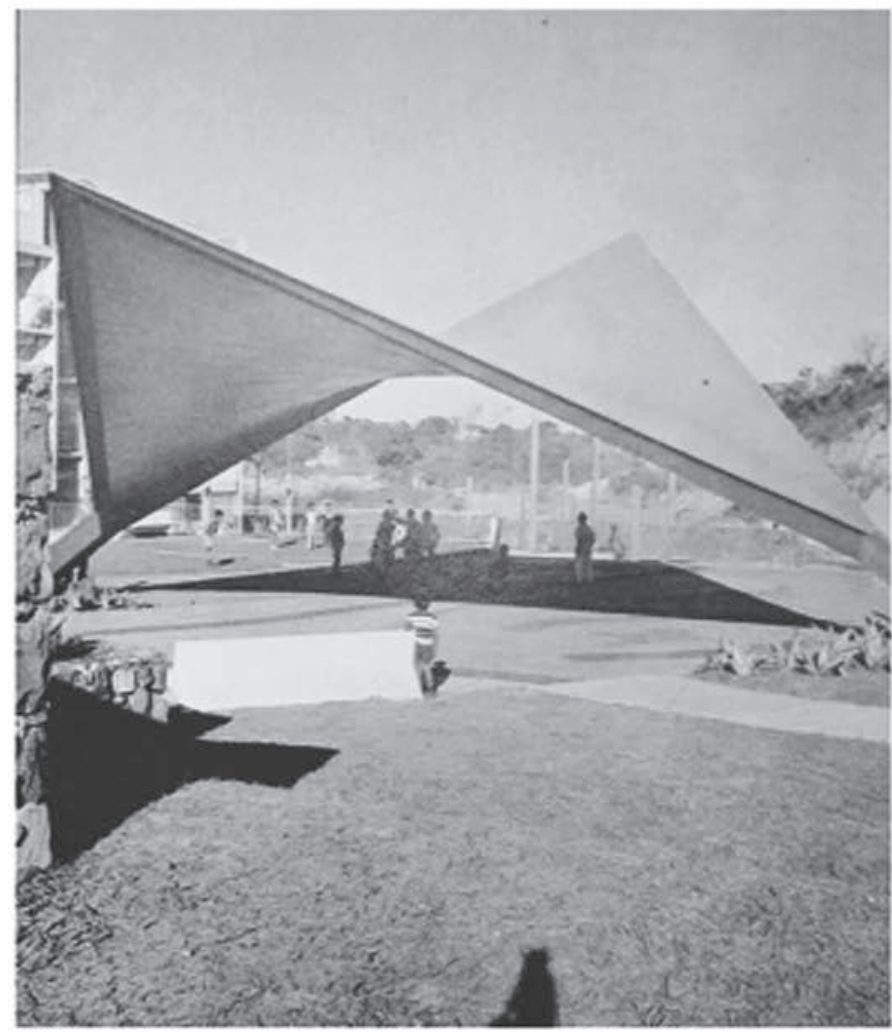

Fig. 2. Obras artísticas promovidas por la DUA: El espejo de agua y La hipérbole (conocida como "Pañuelo") del Centro Urbano Libertad, San Salvador. Fuente: Memoria 1959-1960, IVU. 
Cabe destacar que muchos de estos jóvenes arquitectos y artistas se formaron en el extranjero, ya sea en países europeos o del continente americano como México. Este es el caso de Enrique Salaverría (19222012) y Violeta Bonilla, ${ }^{2}$ quien trabajó bajo la tutela de Diego Rivera durante la realización de las obras en la UNAM $y$, posteriormente, ejecutó junto a su esposo el Monumento a la Revolución de 1948 en El Salvador (Fig. 3), obra del arquitecto Óscar Reyes (Bahamond Panamá, 2012, p.149).

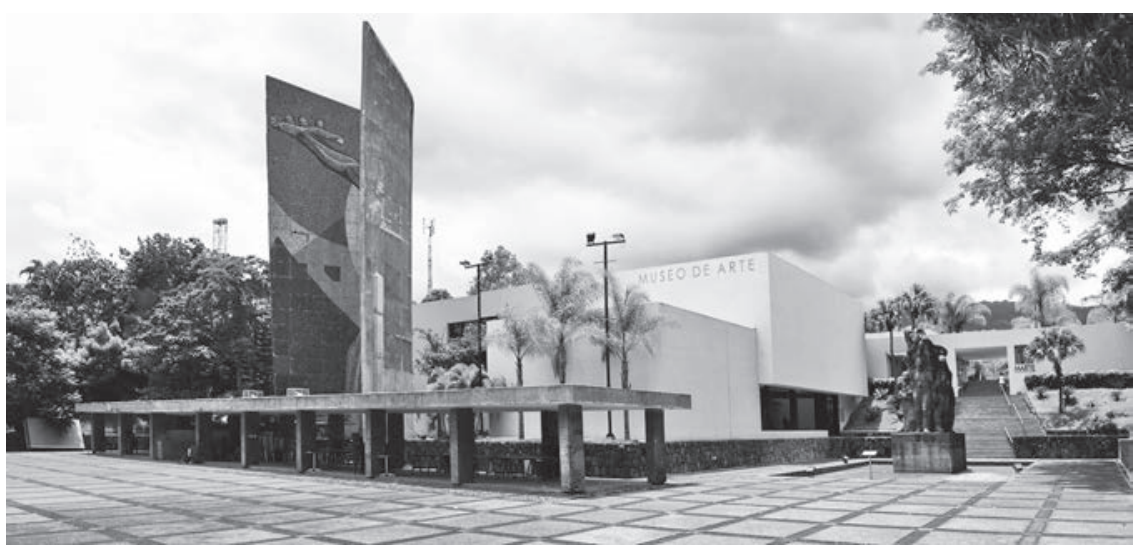

Fig. 3. Monumento a la Revolución de 1948, Oscar Reyes, Kurt Schulze, Violeta Bonilla y Claudio Ceballos (1958). Atrás de contempla la edificación más reciente del Museo de Arte (MARTE). Fuente: Guía de Arquitectura de El Salvador (inédito). Junta de Andalucía/DOE.

\section{Reconocimiento de los valores de la obra de Ricardo Carbonell}

Paralelo a esta realidad que se está gestando en Latinoamérica y particularmente en El Salvador, aparece en el panorama el arquitecto, ingenieroyartista plástico salvadoreño Ricardo Tomás Carbonell (1929), quien realiza una propuesta novedosa de incorporar obras artísticas en viviendas unifamiliares privadas, mientras se están produciendo otros tipos de articulaciones entre arquitectos con artistas a mediados de siglo XX en proyectos de carácter público de gran escala.
Este "profesional joven y estudioso, de conducta tímida producto de su carácter, reservado y juicioso", como lo define su amigo Federico Morales (Morales, 1964, p. 34), comienza sus estudios de ingeniería ${ }^{3}$ en la Universidad de $\mathrm{El}$ Salvador (1947-1953). Paralelamente, estudia en la Academia de Dibujo y Pintura, de Valero Lecha, donde desarrolla sus habilidades en dibujo y pintura al óleo con el más estricto rigor académico (Velasco-Bégué, marzo de 2014, p. 7). Estudiando 
ingeniería desarrolla sus primeras casas en la colonia Flor Blanca, pero al finalizar sus estudios se traslada a Italia para formarse. Se recibe como Doctor en Arquitectura (1954-1958) en la Universidad de Florencia. Continúa sus estudios en artes, específicamente de cerámica en la Escuela Estatal de Sesto Fiorentino, Florencia, en 1956, y de grabado en la Academia de Bellas Artes de Florencia, en 1957. Durante sus estudios en Italia recibe influencias de su maestro, el arquitecto Giovanni Michelucci (1891-1990), personaje importante del modernismo futurista italiano (Comunicación personal con S. Gutiérrez, 7 de julio de 2015).

De estas experiencias formativas, tanto en El Salvador como en Italia,se distinguen tres aspectos importantes: en primer lugar, sus estudios en la Academia de Dibujo y Pintura de Valero Lecha le transmiten sus conocimientos en pintura académica (Fig. 4 y 5), de manera especial el manejo de la luz y las sombras que luego evolucionará al plano bidimensional del mural escultórico. En segundo lugar, su contacto con la vanguardia arquitectónica italiana, especialmente su formación con el maestro Michelucci, incidirá directamente en su concepción de la arquitectura como posibilidad de expresión plástica y, en tercer lugar, sus estudios tanto de ingeniería como de arquitectura y grabado son los que finalmente le permitirán relacionar de manera indisoluble el arte plástico con la arquitectura, la cual concibe como "un lenguaje completo en sí mismo, para expresar realidades existenciales" (Carbonell, 1964, p. 64).

Desde su regreso a El Salvador, en la década de 1960 hasta mediados de la década de 1980, el arquitecto Carbonell desarrolla una serie de viviendas unifamiliares para los grupos de clase media alta que se estaban trasladando hacia los proyectos urbanos de expansión al occidente de la ciudad de San Salvador, como la colonia Flor Blanca. En ellos, logra ejecutar de forma magistral la incorporación de las artes plásticas en la arquitectura, por medio de una serie de murales escultóricos en alto y bajo relieve que integra a sus casas con un perfecto dominio estructural y una gran sensibilidad hacia la experiencia del espacio interior de la vivienda, es decir "vitalizándolo sin destruirlo" (Elías, enero de 2014). 


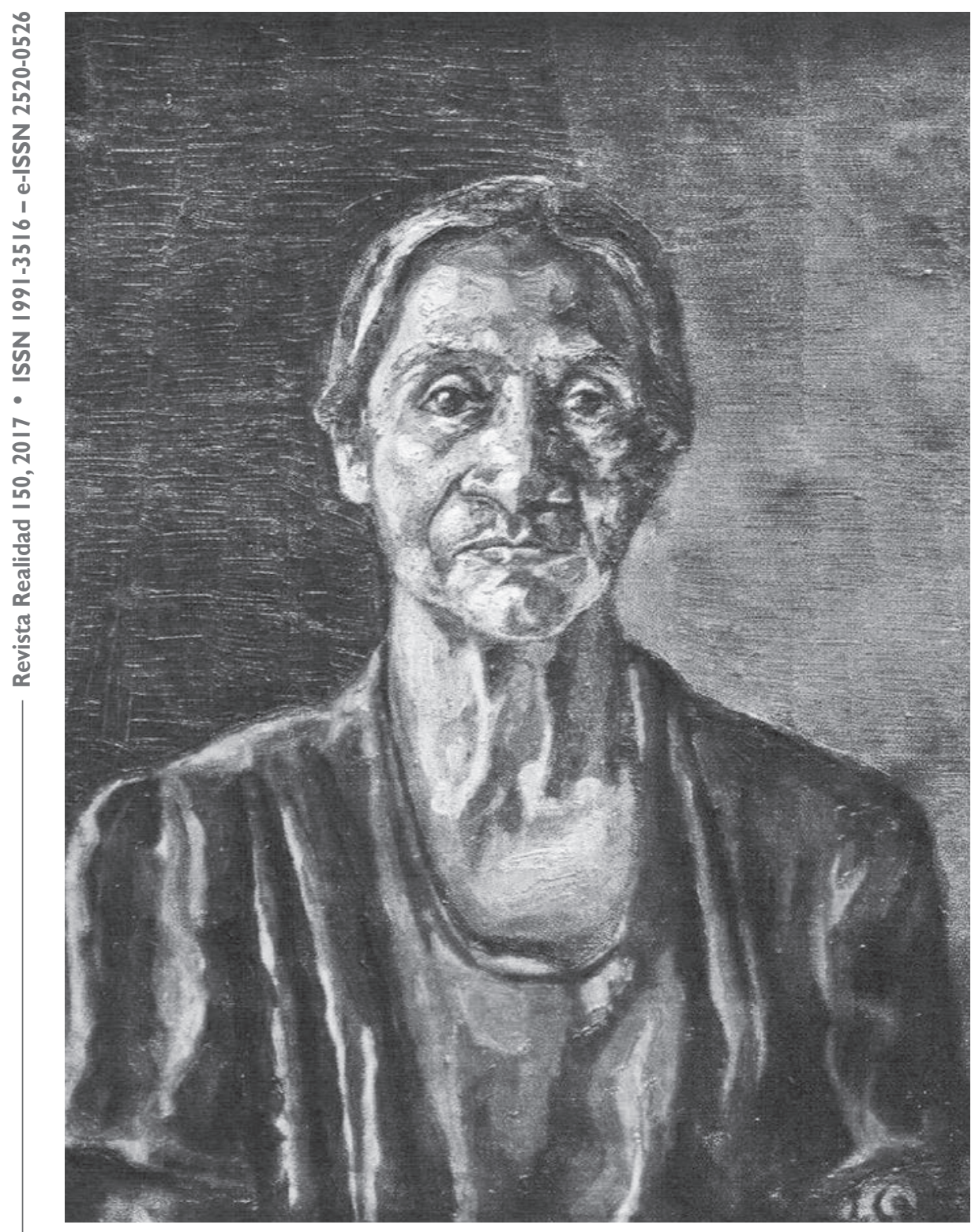

Fig. 4. “Retrato a María”, Ricardo Carbonell (1954). Fuente: Velasco-Begué, 2014. 


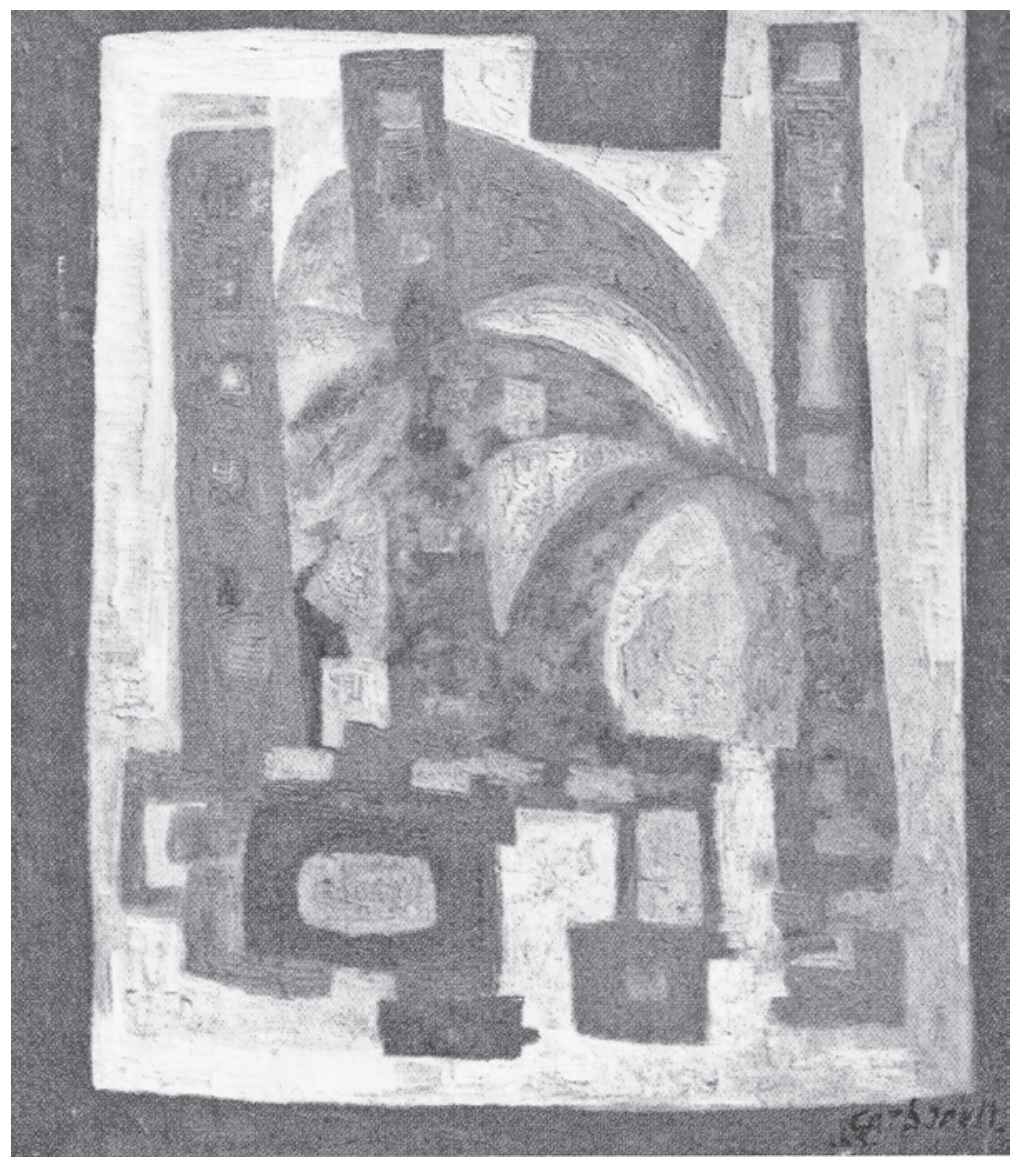

Fig. 5. Abstracto “Ciudad”, Ricardo Carbonell (1965). Fuente: Velasco-Begué, 2014.

Son ejemplos notables de este período tres obras. En primer lugar, cabe mencionar los murales de la Casa Díaz (1965), modelados en concreto armado con un acabado al natural (Fig. 6), cobran vida con el manejo de luces y sombras en los vacíos y llenos de estos inmensos lienzos. Las formas creadas no son del todo figurativas, sin embargo, se logran discernir formas humanas sobre fondos de intenso detalle y texturas, gracias a la rugosidad del concreto (Fig. 7).
En el diseño de la casa, reinterpreta lineamientos de la arquitectura de Frank Lloyd Wright muy en boga por el movimiento moderno internacional (Comunicación personal con S. Gutiérrez, 7 de julio de 2015), la que finalmente se complementa con elementos escultórico-arquitectónicos como bancas de gran plasticidad formal (Fig. 8), gracias al manejo de los materiales y luminarias exteriores que combinan concreto, metal y vidrio. 


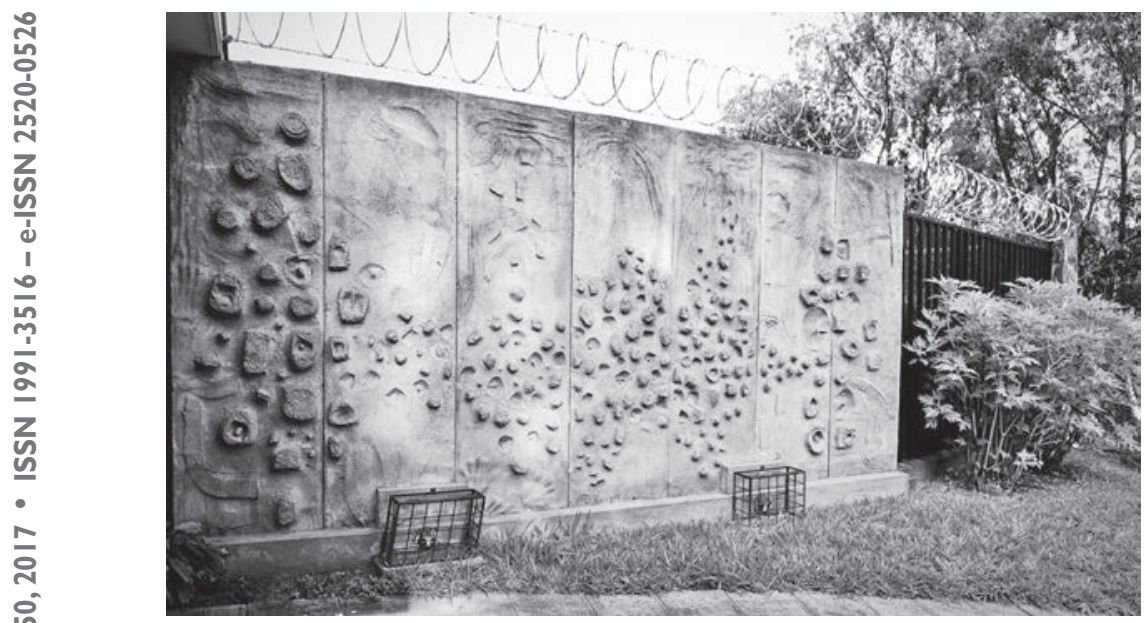

Fig. 6. Mural exterior en la Casa Díaz, Colonia Escalón (1965). Fuente: Guía de arquitectura de El Salvador (inédito).

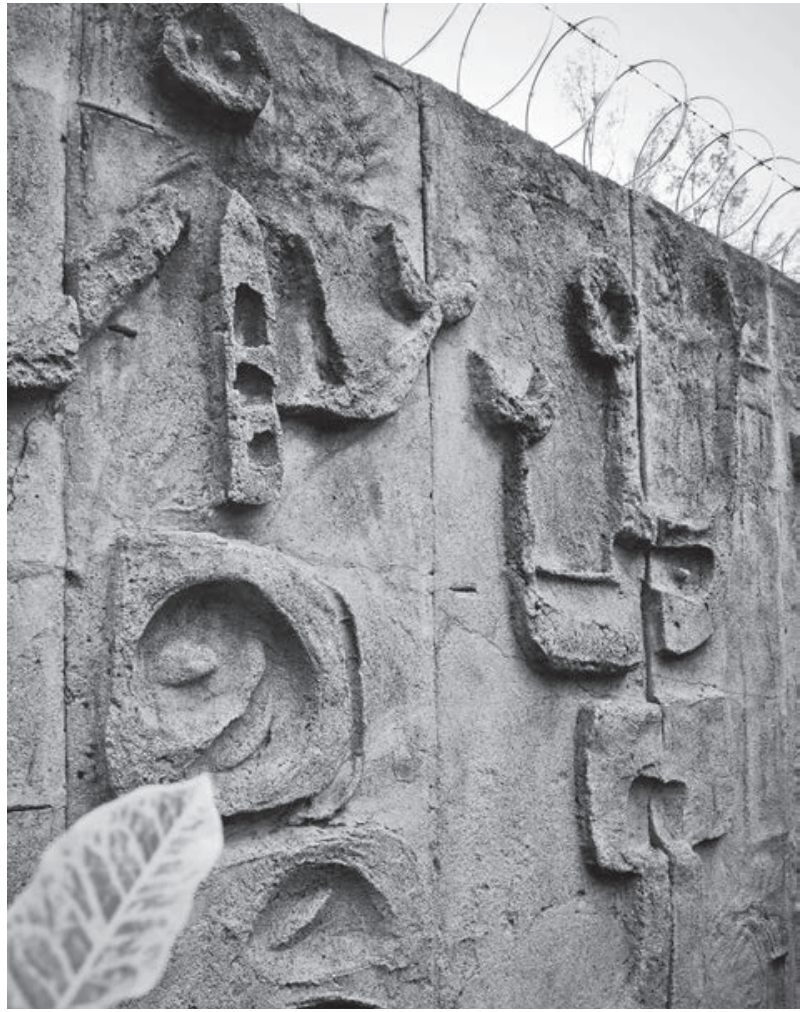

Fig. 7. Detalle de mural interior en la Casa Díaz (1965). Fuente: Guía de arquitectura de El Salvador (inédito). 


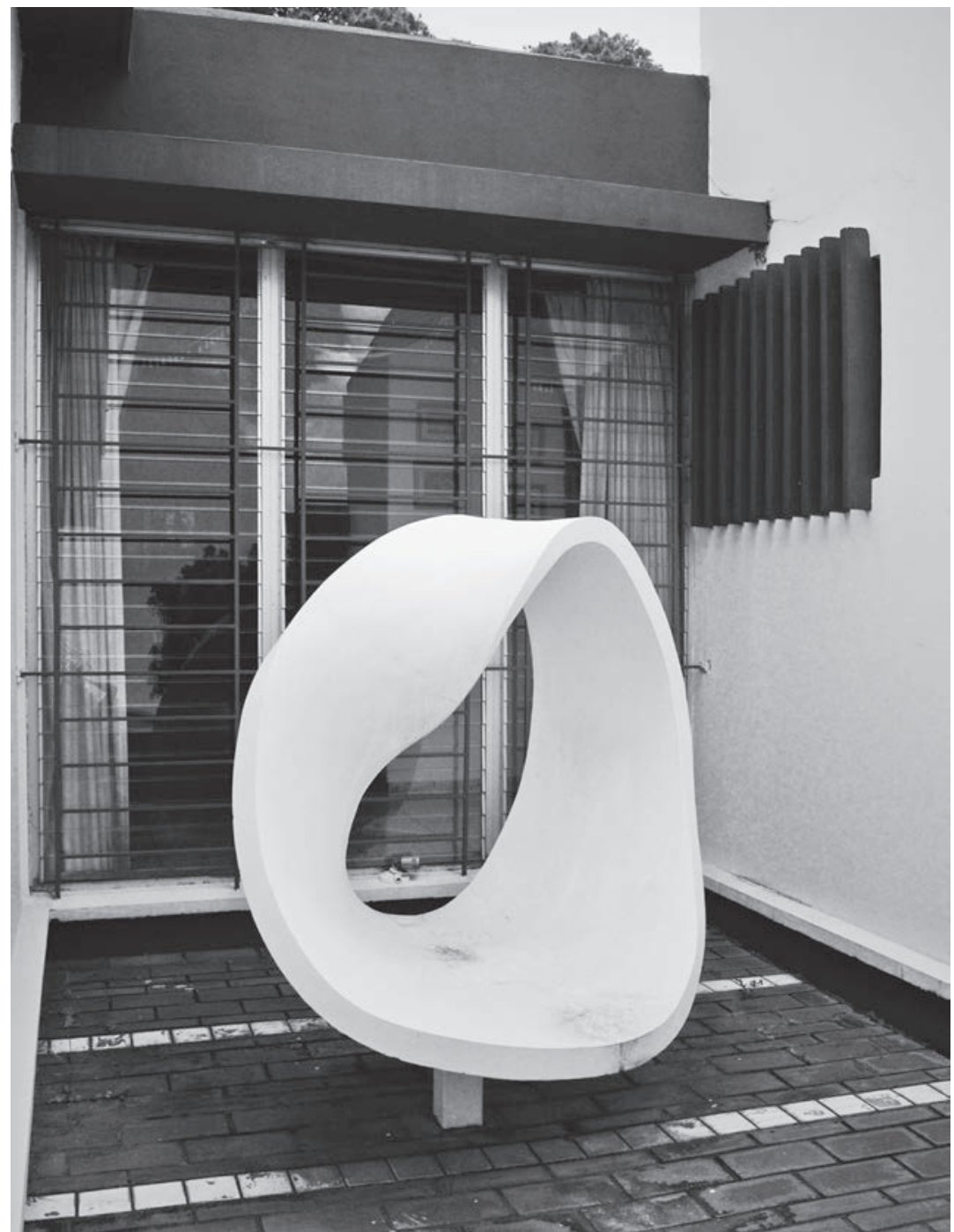

Fig. 8. Detalle de banca escultura al interior en la Casa Díaz (1965). Fuente: Guía de arquitectura de El Salvador (inédito).

Una segunda muestra la livianas entre espacios interiores, encontramos en la Casa Carbonell se presentan como cuadros en alto (1974), la cual se enriquece con relieve de cobre y vitrales de vibrantes murales en concreto, mármol y colores, los cuales fueron elaborados engranajes metálicos de desechos junto a su hija Rosanna Carbonell. De de vehículos (Fig. 9), además de otras esta casa es especialmente notable piezas que, a manera de divisiones el mural de aproximadamente cuatro 
metros de altura que se levanta en el descanso de las escaleras que conducen del nivel de acceso superior al nivel inferior (Fig. 10), similar a los primeros murales en las escuelas que fueron proyectados en la década de 1930 por Juan O’Gorman en México. En esta obra se sintetiza la destreza del modelado de concreto en formas naturalistas de gran expresividad plástica, además, la incorporación del mural en este espacio de transición le confiere una riqueza espacial que altera la percepción del tiempo y la experiencia de los usuarios que transitan por este lugar.
Dota así de valor a un espacio que tradicionalmente es manejado en la arquitectura con formas de poca sutileza y calidad. Por su parte, la casa en sí misma demuestra el diestro manejo de las condicionantes del sitio para su emplazamiento, pues se trata de un terreno en pendiente, al cual es adaptada la vivienda, así dispone de niveles de forma descendente desde la terraza de acceso, bajando al segundo nivel donde se encuentran las habitaciones principales, como comedor, cocina, sala y habitaciones. Por último, se continúa descendiendo hasta la zona de jardines y piscina.

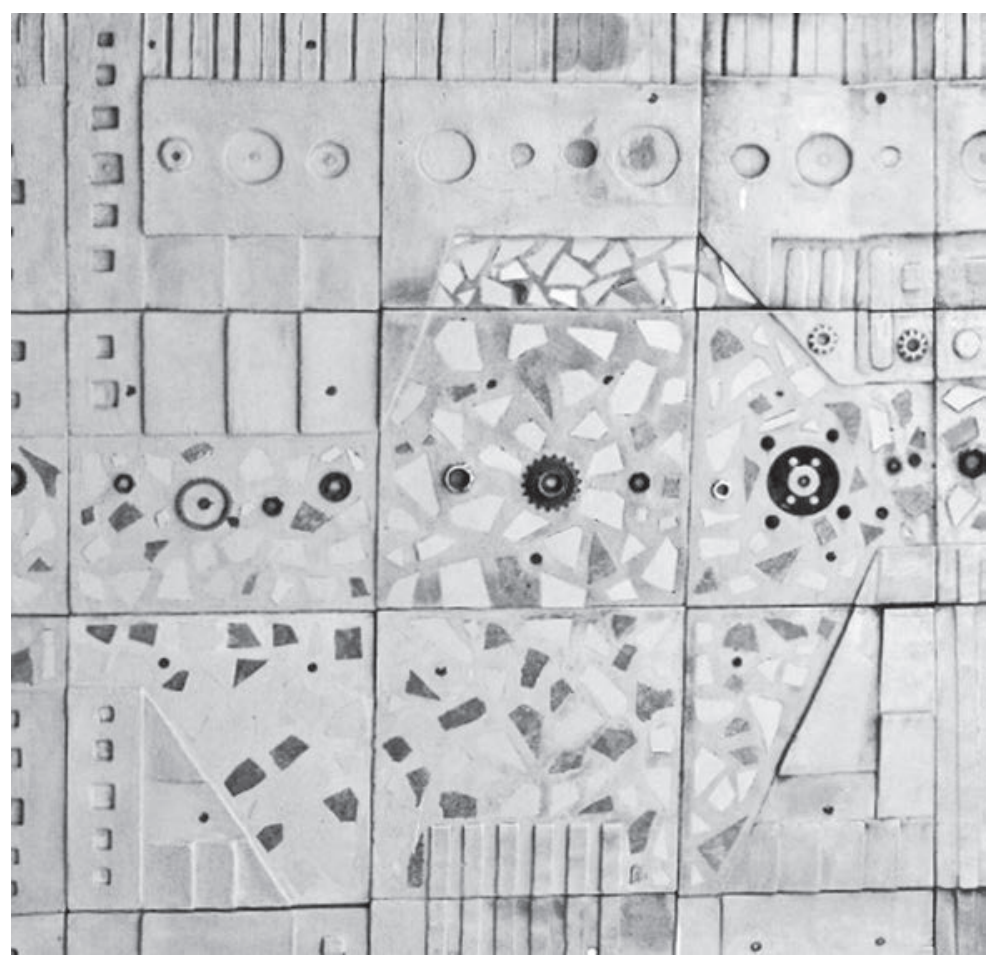

Fig. 9. Detalle de mural exterior en Casa Carbonell (1974). Fuente: Guía de Arquitectura de El Salvador (inédito). Junta de Andalucía/DOE. 


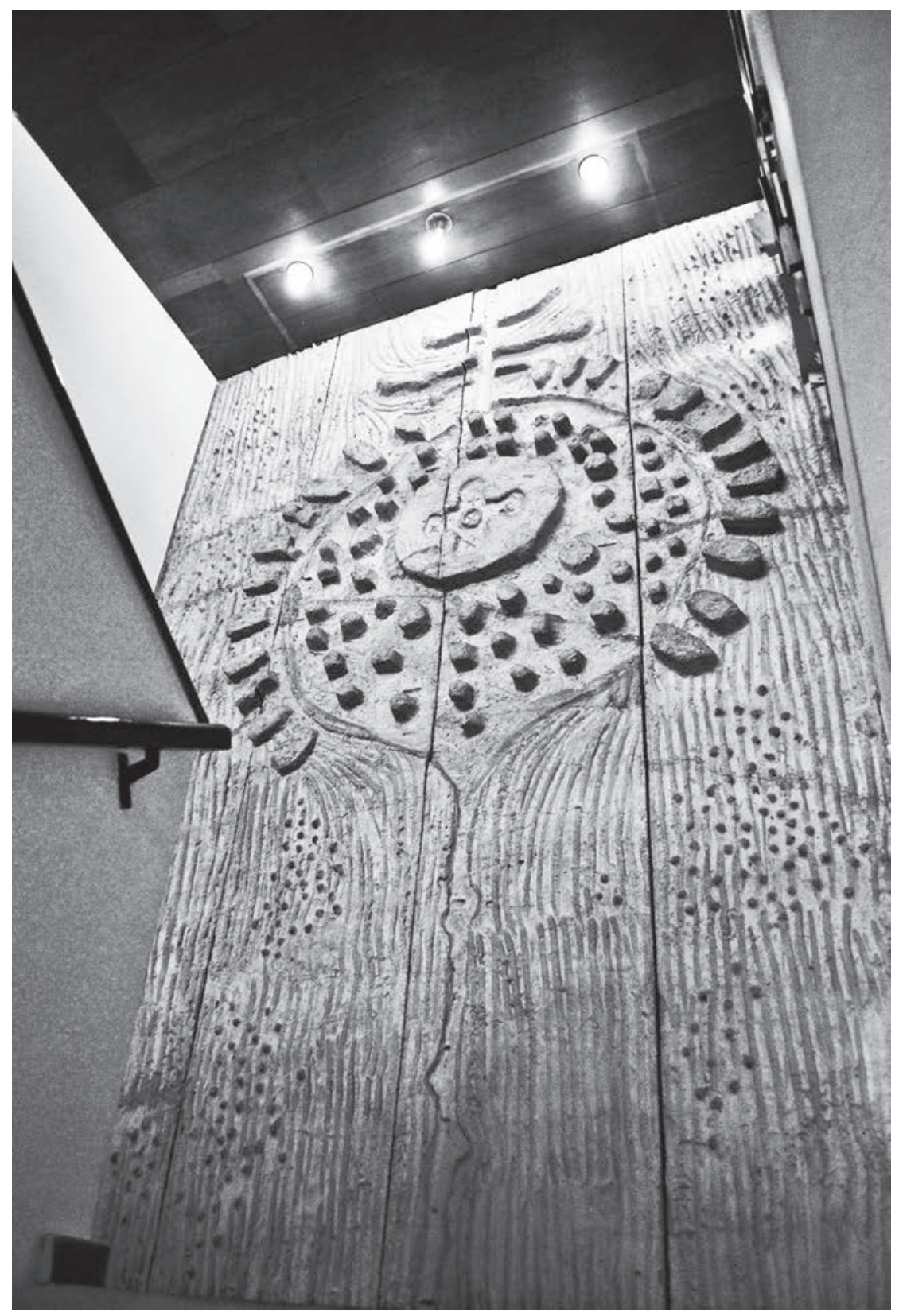

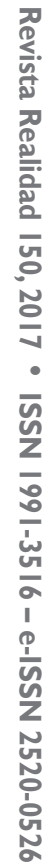

Fig. 10. Mural interior ubicado en el descanso de las escaleras en Casa Carbonell (1974). Fuente: Guía de Arquitectura de El Salvador (inédito). Junta de Andalucía/ DOE. 
Para finalizar, tenemos la tercera muestra que es la Casa Vilanova (1975), en la que se integra un mural forjado en cobre de más de cinco metros de largo (DOE/UCA y Junta de Andalucía, s. f.) $)^{4}$ localizado en el espacio de sala-comedor de la vivienda (Fig. 11). La incorporación de esta pieza contribuye a la percepción del espacio que se fuga por la abertura al final de este salón, el cual da vista hacia una terraza desde la que se contempla parte de la ciudad de San Salvador, es decir, que la obra en este caso acentúa la longitud del espacio que se pierde en el vacío.

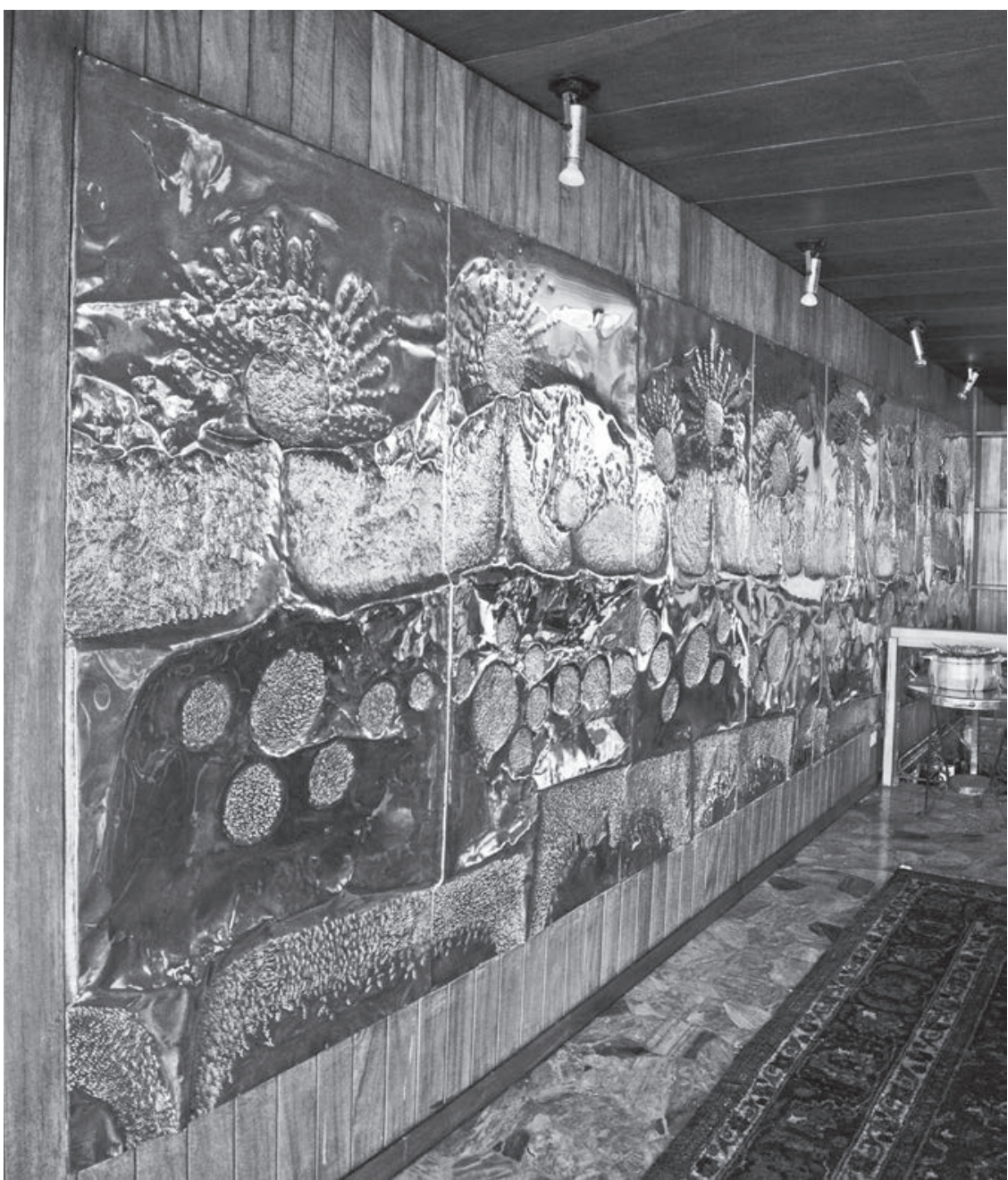

Fig. 11. Mural interior forjado en cobre al interior de la Casa Vilanova (1975). Fuente: Guía de Arquitectura de El Salvador (inédito). Junta de Andalucía/DOE. 
Las tres obras, antes descritas, públicos. $^{5}$ Vale destacar entre ellas el son de los proyectos privados más mural en concreto armado del edificio singulares en la integración plástica de la Corte Suprema de Justicia (Fig. de murales en la arquitectura de Carbonell. Sin embargo, existen otras obras murales al interior de edificios 12), elaborado en 1975 (VelascoBégué, marzo de 2014, p. 40).

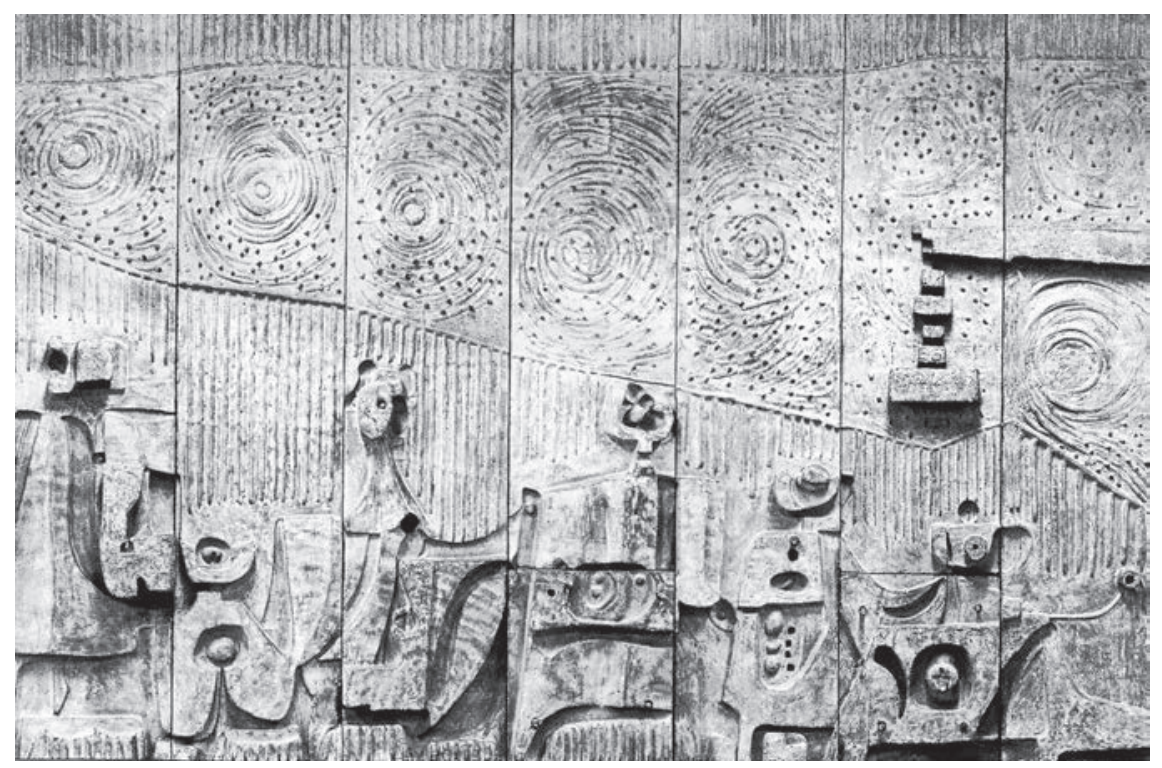

Fig. 12. Detalle de mural al interior del edificio de la Corte Suprema de Justicia (1975). Fuente: Velasco-Begué, 2014.

Lo particular de la obra mural de Carbonell reside en dos aspectos fundamentales, por un lado, en la capacidad de manejar el lienzomuro donde incorpora la obra artística como parte inseparable y fundamental de la estructura de la casa, pues sus murales, a diferencia de un fresco o una pintura en un muro, se enraízan en las fibras constitutivas de la vivienda, en los que a su vez emplea materiales constructivos, muy en boga para la época, como el concreto armado para hacer aún más simbiótica esta relación. Por otro lado, el aporte primordial de estas obras radica en la propuesta única y novedosa de la técnica constructiva, la cual fue desarrollada por el mismo Carbonell, ya que en el país no se habían ejecutado obras de este tipo (Elías, enero de 2014).

La técnica para la construcción de estos murales, que es uno de los grandes aportes tanto para la plástica como para la arquitectura salvadoreña, se asienta en sus 
conocimientos de ingeniería y de la Universidad (Fig. 13). Éste grabado. Para conocer de mejor se convirtió en un significativo manera la forma en cómo se realizan encuentro de gran valor para la este tipo de murales cabe citar la transmisión de conocimientos a una experiencia que se tuvo con un grupo de estudiantes de arquitectura de la Universidad Centroamericana José Simeón Cañas (UCA) en el año 2012, quienes trabajaron directamente con uno de los diseños del arquitecto Carbonell y construyeron bajo su tutoría un mural en el Edificio generación nueva de arquitectos, pero aún más importante fue que abrió nuevamente el camino de la incorporación de las artes plásticas con la arquitectura y también en la arquitectura que les envuelve, como elemento que busca elevar el espíritu de las personas en el día a día. Ignacio Martín Baró en el Campus

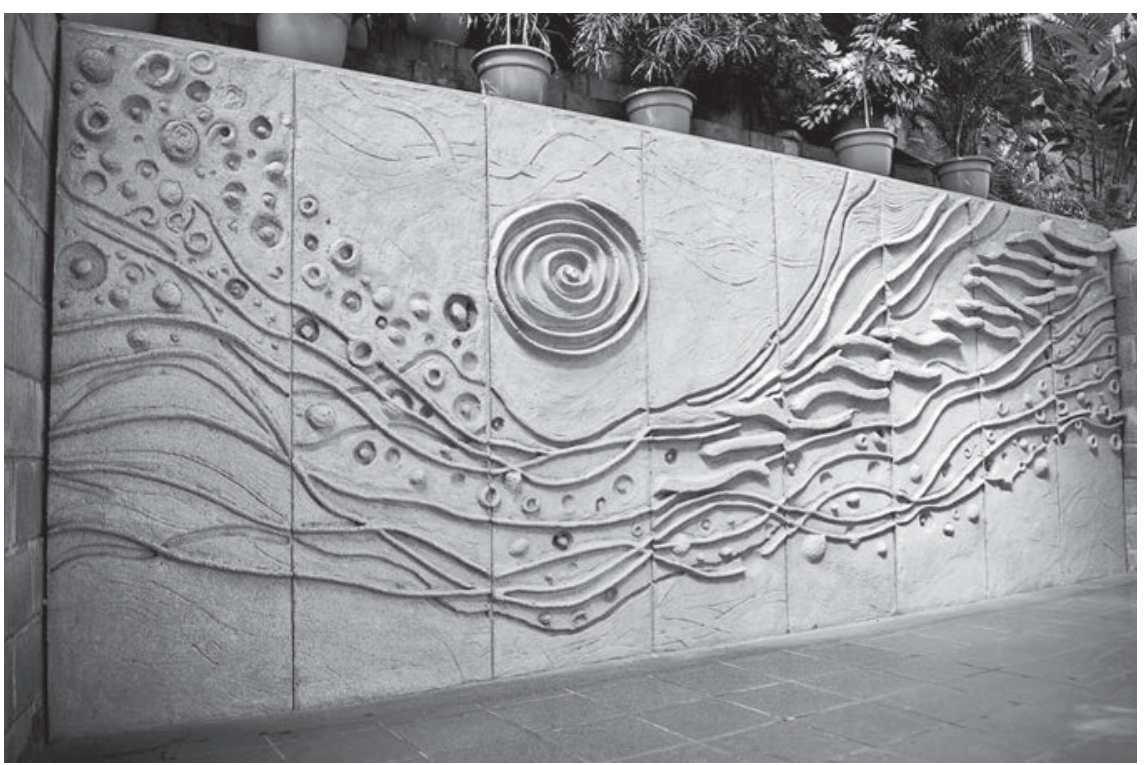

Fig. 13. Mural de Ricardo Carbonell elaborado en 2011, en el Edificio Ignacio Martín-Baró de la UCA. Fotografía de Julio Sánchez.

3.1. Últimos apuntes sobre la obra de Ricardo Carbonell en un contexto artístico de cambio

Para comprender el aporte de Carbonell en el contexto social y cultural de su tiempo, es importante tener en consideración que su ejercicio profesional se desarrolla desde diversos frentes. Por un lado, crea obras pictóricas desde el caballete, por otro, construye viviendas privadas en las cuales mezcla muy diestramente su "ser 
artístico" con su "ser ingenieroarquitecto". Esta particularidad es posible situarla en un período de profundas transformaciones en el mundo de las artes, el cual ya ha sido claramente descrito por José Manuel González con su análisis de la "Estética de las transiciones artísticas: la modernización de la plástica en El Salvador" (González, julio-diciembre de 2013), de las cuales se retoman los siguientes reflexiones que ayudan a precisar las influencias sobre el arquitecto Carbonell.

Por un lado, la consolidación del nuevo Estado salvadoreño ya ha dado comienzo en la primera mitad del siglo XX, cuando se gesta una amplia producción de obras constructivas de diferente naturaleza desde lo privado, pero primordialmente desde lo público, alcanzando a gran parte de la población a lo largo del territorio nacional (Gutiérrez, juliodiciembre de 2013, p. 58). En esta efervescente producción, las artes comienzan a experimentar ciertas transformaciones, las cuales se materializan en obras estéticamente más comprometidas con su tiempo, con lo que se configura una nueva concepción del artista, la cual se manifiesta en nuevos espacios de exhibición como la Sociedad de los Amigos del Arte (1933) o la Galería Forma (1958), que contribuyen a la concepción de la obra artística como objeto de comercialización. Alrededor de estos espacios se configuran nuevos colectivos que contemplan y empiezan a consumir este nuevo arte. Aparecen nuevas formas de enseñanza en el quehacer artístico, como la Academia de Dibujo y Pintura de Valero Lecha (1931-1974), lo que conduce a que "los nuevos creadores plásticos reinterpreten su aprendizaje y comiencen a tomar distancia del imaginario nacionalista" (González, julio-diciembre de 2013, p. 93).

Por otro lado, estas transformaciones se hacen perceptibles en lo novedoso de las creaciones plásticas y toman distancia del rigor académico, pues se experimentan nuevas materialidades y contenidos mucho más en contacto con la realidad. Con esta evolutiva independencia plástica en la década de 1960, se empiezan a configurar "nuevos cruces plásticos significativos como los de pintores-grabadistas, poetas-pictorialistas, muralistaspintores, arquitectos-modeladores, arquitectos-muralistas, entre otros" (González, julio-diciembre de 2013, p. 97). En estos últimos tres cruces son notorias las obras de Carbonell, quien realiza su práctica desde el papel de arquitecto-muralista en sus murales escultóricos, o en un cruce de tres disciplinas mucho más complejas como el de arquitectomuralista-pintor, observable en sus obras de gran variedad y naturaleza. 


\section{Consideraciones finales}

El "ser" de Ricardo Carbonell se construye debido a las influencias de su contexto, al estar en contacto con las nuevas generaciones de artistas que exhiben y venden sus obras pictóricas en las emergentes salas de exposiciones y galerías de arte, centros de importante intercambio y reflexión cultural, que le permiten entrar en contacto con nuevos públicos que valoran el trabajo del "nuevo artista experimental", pero con fuerte formación académica. En el caso de Carbonell, se forma desde su carrera profesional de ingeniero, doctor en arquitectura y su paso por la Academia de Dibujo y Pintura de Valero Lecha, donde obtiene la destreza y dominio de las técnicas plásticas que plasmará posteriormente en sus obras de contenidos más experimentales y únicos.

Estas experiencias personales y el contexto de transformación artística, le permiten explorar nuevos lenguajes y medios en los que el lienzo sobre el caballete se queda corto, por lo que crea su propio espacio de experimentación gracias a su práctica de arquitecto-ingenieroconstructor, lo que le permite ahondar en las inmensas posibilidades del "muro-lienzo", que moldea con los materiales del momento: acero, concreto, cerámica, entre otros. Éstos le facilitan la creación de obras artísticas íntimamente ligadas con la estructura, que aportan mayor vitalidad la experiencia del espacio, tanto al interior de sus edificaciones como al exterior. Este aporte plástico es donde puede comprenderse el profundo valor estético-espacial de la arquitectura de Carbonell, un valor que es único en una época de generalizada modernidad internacional.

Con todo ello, se puede establecer que la obra mural, equilibrada y serena de Ricardo Carbonell realiza tres grandes aportes a la historia de la plástica y la arquitectura salvadoreña: en primer lugar, el ejecutar proyectos residenciales de carácter privado le permite explorar contenidos y técnicas de formas más libres y experimentales que los casos promovidos por el Estado. En este sentido, debe aclararse que algunos de los murales ejecutados en estas viviendas tuvieron que ser financiados por el mismo artista, pues era incomprendido y subestimado por los propietarios, que para ese momento no reconocían el profundo valor de estas obras en el diseño de los espacios. ${ }^{6}$ En segundo lugar, su gran aporte se encuentra en la creación de una técnica artística novedosa para realizar este tipo de obras. Su mayor contribución radica, en este sentido, en la transmisión de sus conocimientos a nuevas generaciones de arquitectos, garantizando de esta manera su 
trascendencia en el tiempo y en el espacio, con nuevas exploraciones y propuestas. Finalmente, el tercer aporte es que la obra mural de Carbonell resulta ser indisoluble de la estructura de los inmuebles, formando parte constitutiva de la arquitectura. El lazo se estrecha y crea una unidad formal, rica y expresiva.

A lo largo de los planteamientos realizados hasta el momento que son: en primer lugar, la consideración de la arquitectura como rama del arte; en segundo lugar, el encaje de la obra mural de Carbonell en un mismo período de exploración del muro desde el contexto latinoamericano más cercano del momento $y$, en tercer lugar, el reconocimiento de las singularidades de la obra arquitectónica y muralista de Ricardo Carbonell, puede encontrarse la base para definir con mayor claridad el aporte que realiza la obra mural de este artista-arquitecto-ingeniero al fortalecimiento de la identidad arquitectónica en El Salvador. Desde una personalidad reservada y tranquila, Carbonell aprovecha las bondades de su tiempo para crear obras únicas desde su ejercicio, por supuesto, sin olvidar a personas tan importantes como Rubén Martínez en la iglesia El Rosario, en el Centro Histórico de San Salvador, que también personaliza la figura de arquitecto-artista-constructor y de quien también resulta urgente valorizar su inigualable obra.
Por todo lo anterior es posible reconocer en las obras de Carbonell ciertos valores culturales que podrían contribuir con procesos futuros de protección de sus creaciones, de lo contrario pueden correr con el mismo destino que el mural de 1960, obra de Carlos Cañas (1924 - 2013) en el edificio de la Federación de Cajas de Crédito de Juan José Rodríguez (1935), el cual fue demolido tras una de las remodelaciones que sufrió el inmueble. Esta situación debe, además, valorarse desde una perspectiva mucho más amplia del reconocimiento de las obras del movimiento moderno como parte del patrimonio cultural de los pueblos, ya que evidentemente se trata de un período en la historia que se encuentra muy cercano a la época actual, y en donde la corta distancia complica reconocer sus profundos aportes. Esta es una de las principales razones que explican el desaparecimiento de la arquitectura moderna en el paisaje urbano, pues no existe mayor preocupación o regulación sobre el patrimonio.

Sumado a lo anterior, debe destacarse que en el caso de la arquitectura habitacional, la regulación resulta aún más complicada por la dificultad de monitoreo y protección dada por su misma condición "privada", que a su vez limita naturalmente su disfrute por parte del público en general. Esta situación, en el caso de El Salvador, se exacerba por la "neurosis 
del muro exterior perimetral" que aísla a la arquitectura residencial de su necesaria relación con el entorno urbano al cual pertenece.

Indiscutiblemente, son muchos los paradigmas que deben ser superados para que se logre una correcta y eficiente protección del patrimonio cultural de la modernidad, sin embargo, se puede hacer un importante aporte desde el reconocimiento consciente de los valores de esta arquitectura para motivar acciones de preservación y salvaguarda mucho más palpables para el caso de las edificaciones de carácter privado, como es la situación de la arquitectura habitacional de Carbonell.

Basándose en lo anterior, se pueden definir algunos valores culturales para el conjunto de la obra mural de Ricardo Carbonell, la cual no puede ser aislada de las edificaciones que las contienen, ya que estas piezas cobran sentido a partir de su relación con el espacio y con las fibras constitutivas de los inmuebles. Es así que, para realizar esta valoración, ${ }^{7}$ se puede comenzar apreciando que las piezas son el producto de un autor reconocido de gran trayectoria y reconocimiento a nivel nacional, es decir que se puede destacar su valor de autoría. En segundo lugar, los diseños abstractos y naturalistas construidos a partir de la creación de composiciones volumétricas de altos y bajos relieves que generan sombras, acentuadas por la fuerte expresividad de las texturas en el manejo de los materiales, les confiere un valor estéticoarquitectónico que fue logrado desde la interacción con el medio natural y los espacios contenedores. Con base al anterior valor, es posible identificar una tercera categoría, la cual se relaciona con la técnica y los materiales empleados, los cuales son producto de la invención y conocimientos del autor en vincular tan estrechamente la obra plástica en la arquitectura o construcción de los inmuebles, con ello se perfila entonces el valor tecnológico. En cuarto lugar, y para finalizar el rápido ejercicio de valoración cultural sobre la obra mural de Ricardo Carbonell, se debe destacar la vinculación de su obra con el contexto social, cultural y político de la época en la cual fueron creadas. Sobre este tema cabe resaltar el paralelismo -descrito anteriormente - con las vanguardias plásticas en el resto del continente, particularmente con el movimiento de la integración plástica en México, donde además deberá considerarse el contexto artístico salvadoreño que logra impulsar el reconocimiento de este joven arquitecto en el medio artístico de efervescente cambio.

Para finalizar, en vista de las reflexiones anteriores entorno a la obra plástico-arquitectónica en las viviendas privadas del arquitecto Ricardo Carbonell en el fructífero e intenso período de la modernidad 
arquitectónica en El Salvador, resulta oportuno citar al arquitecto Lucio debería ser el papel del arquitecto Costa con una reflexión sobre lo que arquitectura:

[...] lo importante es que la propia arquitectura sea concebida y ejecutada con conciencia plástica, es decir, QUE EL ARQUITECTO SEA, ÉL MISMO UN ARTISTA. Porque sólo entonces el pintor o el escultor tendrá condiciones de integrarse en el conjunto de la composición arquitectónica como uno de sus elementos constitutivos, ahora dotado de un valor plástico autónomo [...]. (Costa, 1995, pp. 266-267).

\section{Referencias bibliográficas}

- Bahamond Panamá, A. M. (2012). Procesos del arte en El Salvador. San Salvador, El Salvador: Dirección de Publicaciones e Impresos.

- Carbonell, R. (1964). Arquitectura y su integración con las artes plásticas. Arquitectura (Órgano del Colegio Salvadoreño de Arquitectos, №. 4), pp. 63-65.

- Carta de Cracovia. (2000). Principios para la conservación y restauración del patrimonio construido. Cracovia: Participantes de la Conferencia Internacional Cracovia.

- Costa, L. (1995). Art, manifestation normale de vie. En Costa L. (Ed.), Registro de una vivencia. (pp. 266-267). São Paulo, Brasil: Empresa das Artes.

- Dirección Nacional de Patrimonio Cultural. (2013). Instructivo para la valoración y medidas de protección de bienes culturales inmuebles. San Salvador, El Salvador: Secretaría de Cultura de la Presidencia.

- DOE/UCA y Junta de Andalucía. (S. F). Guía de Arquitectura de El Salvador. España.

- Elías, K. M. (Productor). (Enero de 2014). Arte y Fe Network: Ricardo Carbonell. [Programa de televisión]. El Salvador: Canal 8.

- Garza,C.R. (2010). La Ciudad Universitaria en el movimiento de integración plástica en México. Bitácora Arquitectura ( $\left.\mathrm{N}^{\circ} .21\right)$.

- Giménez, G. (2005). La cultura como identidad y la identidad como cultura. México: Instituto de Investigaciones Sociales de la UNAM. 
- González, J. M. (Julio-diciembre de 2013). Estética de las transiciones artísticas: la modernización de la plástica en El Salvador. Identidades. Revista de Ciencias Sociales y Humanidades (N. 7), pp. 82-105.

- Gutiérrez, S. (2012). Arquitectura Moderna en El Salvador. En CONIA, Memoria del II Congreso de Ingeniería y Arquitectura. San Salvador, El Salvador: UCA Editores.

- Gutiérrez, S. (Julio-diciembre de 2013). Premisas para comprender la arquitectura moderna en El Salvador. Identidades. Revista de Ciencias Sociales y Humanidades ( $\left.N^{\circ} .7\right)$, pp. 41-57.

- Heredia, J. M. (Agosto de 2014). “Integración plástica” o el problema de la orientación (I). Arquine Revista Internacional de Arquitectura y Diseño.

- Humanes,A.(2009).Arquitectura moderna y patrimonio mundial. Patrimonio Cultural de España (№. 2), pp. 217-231.

- Marín, C. M. (2006). Biblioteca central: libros, muros y murales, 50 aniversario. México: UNAM.

- Morales, F. (1964). Exposición de Ricardo Carbonell. Arquitectura (№.1).

- Pevsner, N. (1957). Esquema de la arquitectura europea. Buenos Aires: Ediciones Infinito.

- Rivera, C., Rivera, S., Rodas, J. y Ruiz, G. (2013). Análisis de la modernidad arquitectónica en El Salvador: Obras selectas. San Salvador, El Salvador: UCA Editores.

- Sato, A. (Julio de 2003). La Síntesis de Carlos Raúl Villanueva. Revista Urbana (N०.89), p. 33.

- UNAM. (2014). Fundación UNAM. Consultado el 12 de mayo de 2015, recuperado de www.fundacionunam.org.mx

- Velasco-Bégué, M. (Ed.). (Marzo de 2014). Ricardo Carbonell. Exposición retrospectiva de la Sala Nacional de Exposiciones.

- Villanueva, C. R. (Octubre de 1962). La síntesis de las artes, "Liason entre les arts. L'Histoire d'une époque (1890-1962)”. Royaumont, Francia.

\section{Notas}

1 Un reconocimiento que desde hace varias décadas se ha manifestado en la incorporación de las obras plásticas de Ricardo Carbonell en muestras colectivas, galerías, salas de exposición y, siendo la más reciente, la Retrospectiva de su obra en 2014, en la Sala Nacional de Exposiciones (Velasco-Bégué, marzo de 2014). 
2 El personaje de Violeta Bonilla es sumamente interesante de comprender dentro de este contexto, pues estudia en México durante el desarrollo del movimiento muralista (Bahamond Panamá, 2012, p. 149). Por esa línea puede intuirse alguna influencia de este efervescente contexto en la materialización de sus obras en El Salvador, las cuales que recurren al empleo de piedras naturales como es el caso del Monumento a la Revolución de 1948, o los murales de Don Quijote y Sancho Panza en la Plaza Miguel de Cervantes junto a la ex Casa Presidencial 6 [antigua Casa] en San Jacinto.

3 Comienza a estudiar Ingeniería civil, pues aún no existía la carrera de arquitectura, la cual es fundada en el año de 1954 (Rivera, Rivera, Rodas y Ruiz, 2013).

4 La investigación para realizar la "Guía de Arquitectura de El Salvador" fue hecha entre los años 2009-2012 por el Departamento de Organización del Espacio de la Universidad Centroamericana "José Simeón Cañas" y financiada por la Junta de Andalucía, España, la cual se encuentra todavía pendiente de publicación.

El arquitecto Carbonell se dedicó a trabajar en proyectos privados, por lo que sus obras artísticas en edificios de carácter público consistieron en colaboraciones exclusivas y puntuales en esta área, sin tener relación directa en el proyecto constructivo de los edificios (Elías, enero de 2014).

Comunicación personal con Sandra Gutiérrez Poizat, 7 de julio de 2015.

7 Para realizar esta valoración se ha empleado el "Instructivo para la valoración y medidas de protección de bienes culturales inmuebles" elaborado en 2013 por la Dirección Nacional de Patrimonio Cultural, fundamentado en las cartas y convenios internacionales sobre Patrimonio Cultural (Dirección Nacional de Patrimonio Cultural, 2013). 